\title{
The humanistic and economic burden of chronic wounds: A systematic review
}

Maja Olsson, RN, $\mathrm{MPH}^{1}$; Krister Järbrink, $\mathrm{PhD}^{1}$; Ushashree Divakar, $\mathrm{MSc}^{1}$; Ram Bajpai, $\mathrm{PhD}^{1}$; Zee Upton, $\mathrm{PhD}^{2,3}$; Artur Schmidtchen, $\mathrm{MD}, \mathrm{PhD}^{3,4}$; Josip Car, $\mathrm{MD}, \mathrm{PhD}^{1,5}$

${ }^{1}$ Centre for Population Health Sciences (CePHaS), Lee Kong Chian School of Medicine, Nanyang Technological University, Clinical Sciences Building, 11 Mandalay Road, Singapore 308232, Singapore

${ }^{2}$ Institute of Medical Biology, Agency for Science, Technology and Research (A*STAR), Singapore 138648, Singapore

${ }^{3}$ Dermatology and Skin Biology Programme, Lee Kong Chian School of Medicine, Nanyang Technological University, 59 Nanyang Drive, Experimental Medicine Building, Singapore 636921, Singapore

${ }^{4}$ Division of Dermatology, Department of Clinical Sciences, Lund University, 22184 Lund, Sweden

${ }^{5}$ Global eHealth Unit, Department of Primary Care and Public Health, School of Public Health, Imperial College London, 3rd floor Reynolds Building, St Dunstan's Road, London W6 8RP, UK

This article has been accepted for publication and undergone full peer review but has not been through the copyediting, typesetting, pagination and proofreading process, which may lead to differences between this version and the Version of Record. Please cite this article as doi: 10.1002/wrr.12683 


\section{Correspondence to}

Associate Professor Josip Car, Centre for Population Health Sciences (CePHaS), Lee Kong

Chian School of Medicine, Nanyang Technological University, Clinical Sciences Building, 11

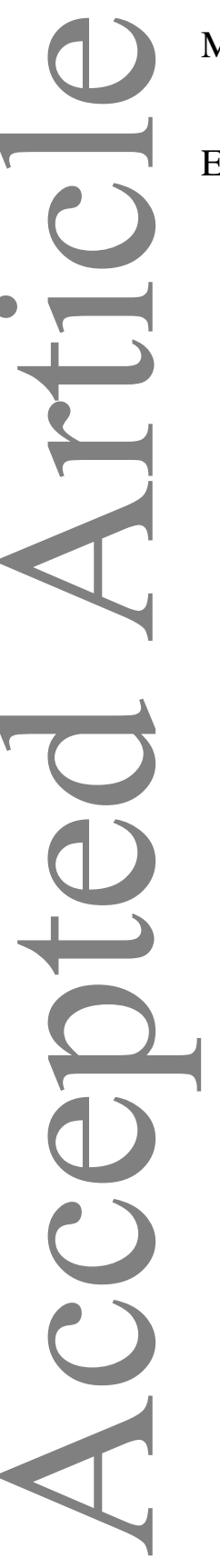

Mandalay Road, Singapore 308232, Singapore

E-mail: josip.car@ntu.edu.sg 


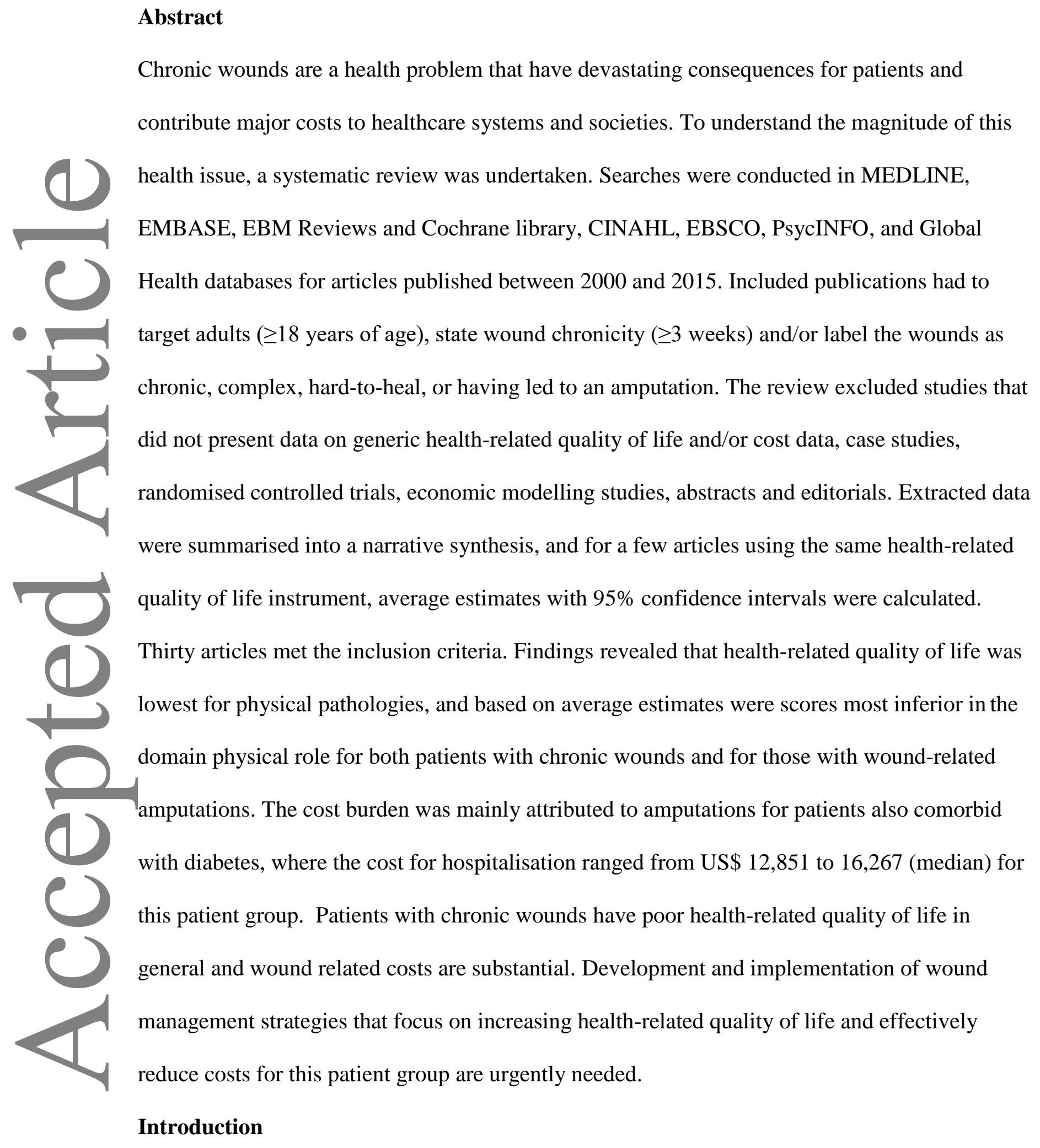

Chronic wounds, hard-to-heal or difficult-to-heal wounds/ulcers, are defined as wounds that do 
not heal properly during an amount of time that normally should be sufficient for healing. ${ }^{1}$ There is no pre-established consensus for the duration of chronicity, ${ }^{2}$ and the wounds are often managed as a comorbidity of other conditions. ${ }^{3}$ Chronic wounds have significant humanistic and economic burdens, both at an individual (e.g. quality of life) ${ }^{4}$ and a societal level (e.g. healthcare costs). ${ }^{1,5-7}$ The humanistic burden, often presented as health-related quality of life (HRQoL), reflects specific dimensions of health (e.g. physical and psychological), ${ }^{8}$ and is assessed in health economic studies to understand and estimate the burden of patients suffering from a condition or disease. ${ }^{8}$ Chronic wounds are also associated with major economic burdens, comprising of direct (medical and health care costs) and indirect costs (productivity losses, e.g. sick leave and early retirement) to the society. ${ }^{1,5-7}$ Treatment costs for chronic wounds are substantial and are estimated to account for approximately $1-3 \%$ of the total healthcare expenditure in developed countries. ${ }^{1,5,7}$ However, this is probably an underestimation since more recent studies report even greater costs. ${ }^{6}$ For example, Wales was estimated to have a chronic wound prevalence of $6 \%$ in the year 2012-2013, corresponding to $5.5 \%$ of National Health Service expenditure, ${ }^{6}$ and in the United Kingdom as a whole, the cost associated with wound management was estimated to be $£ 4.5-5.1$ billion in $2012 .^{9}$ In the United States it is reported that over 6.5 million patients with wounds cost the health care system US\$ 25 billion annually. ${ }^{7}$

The humanistic and economic burden of chronic wounds is underappreciated and growing due to an ageing population, and earlier development of chronic illnesses such as diabetes, etc. ${ }^{7}$ A recent systematic review explored the cost-of-illness for chronic wounds but did not specify how chronicity in the included studies was defined, nor explored the humanistic burden, which is crucial to understand the magnitude of the problem. ${ }^{10}$ 
No previous systematic review has assessed both the humanistic and economic burden of chronic wounds. This systematic review with a definition for chronicity (duration $\geq 3$ weeks) aimed to explore the impact of chronic wounds on HRQoL for patients and their caregivers and to explore the economic impact of the condition measured as cost-consequences to society.

\section{Materials and methods}

\section{Search strategy and selection criteria}

This systematic review followed the PRISMA statement, ${ }^{11}$ and systematic searches were carried out in the MEDLINE, EMBASE, EBM Reviews and Cochrane library, Cumulative Index to Nursing and Allied Health Literature (CINAHL, EBSCO), PsycINFO and Global Health databases during April 2016. ${ }^{12}$ The search was limited to articles published between January 2000 and December 2015. Search strategies were created in collaboration with dermatology- and wound-specialist and medical research librarians. ${ }^{12}$

Studies targeting adults $\geq 18$ years of age having chronic wounds specified by wound duration ( $\geq 3$ weeks), or labelled as chronic, complex, hard-to-heal or having led to an amputation were included. Wounds that failed to heal within three weeks were considered chronic, as ulcers not reducing in size after four weeks are probable to become chronic. ${ }^{13}$ Since there is no preestablished consensus for chronicity and when a wound generally is considered as chronic a duration of $\geq 3$ weeks was deemed appropriate to capture hard-to-heal wounds across various wound aetiologies. ${ }^{2}$

HRQoL articles had to report data obtained from a generic instrument (e.g. The MOS 36-item Short-Form Health Survey (SF-36), SF-12, SF-6D and EuroQol-5D (EQ-5D)), and for economic burden studies, cost data had to be presented. Only peer-reviewed, full-text publications in 
English were included.

The review excluded large non-chronic wounds (e.g. surgical wounds and skin tumours that due to size and malignity require a longer time to heal), and solely disease-specific HRQoL studies, case studies, randomised controlled trials, economic modelling studies, abstracts, or editorials. The included publications were imported to Endnote X7C, and duplicates were removed. Two reviewers independently screened the titles and abstracts to identify studies with potential for inclusion, and full-text copies of relevant articles were obtained and assessed for eligibility for final inclusion. Discrepancies in assessment were resolved by discussion between the reviewers, with reasons for exclusion noted.

\section{Data extraction}

Data extraction was done independently by two reviewers and documented in extraction forms inspired by the Joanna Briggs Extraction Form for Economic Evaluations. ${ }^{14}$ The methodological quality was assessed by using the Joanna Briggs Institute (JBI) Critical Appraisal Tool: Checklist for Prevalence studies, which is mainly developed for prevalence data but also applicable for quality of life data such as HRQoL, ${ }^{15,16}$ and Drummond and Jefferson's Checklist for Economic Evaluation $^{17}$ for cost articles. HRQoL- and cost data were reviewed separately and key findings were summarised. The results were presented as a descriptive narrative synthesis including pooled-analyses for HRQoL outcomes when homogeneity allowed (i.e. when data were uniform enough to enable comparisons).

\section{Statistical analysis}


No formal meta-analysis was performed due to the large heterogeneity (probably due to different kind of wounds, severity and method of evaluation etc.) between studies. For HRQoL, weighted average with corresponding $95 \%$ confidence interval (CI) was calculated for SF-36 domains separately for chronic wounds and amputation groups. Weighted mean and corresponding standard deviation were calculated by $\sum_{i}^{T} n_{i} m_{i} / \sum_{i}^{t} n_{i}$ and $\sqrt{\left[\sum_{i}^{T}\left(n_{i}-1\right)\left(s_{i}\right)^{2} /\left(\left(\sum_{i}^{T} n_{i}\right)-T\right)\right]}$, respectively, where $\underline{n}_{\mathrm{i}}$ is the sample size of study group $i, m_{\mathrm{i}}$ is the mean of study group $i, s_{i}$ is the standard deviation of study group $i$, and $T$ is the number of studies. For missing standard deviation values corresponding to a SF-36 domain, we used largest available standard deviation in the group of studies to enable weighted standard deviations. ${ }^{18}$ Subgroup analyses were conducted for chronic wounds (excluding amputation groups due to lack of control group and less than three studies in total) when control groups were present (see supplementary Figure 1). No formal statistical comparisons was performed for the subgroup analysis of SF-36 domain scores in order to avoid misleading conclusions as recommended in the Cochrane Handbook for systematic reviews. ${ }^{19}$ A value of $\mathrm{p}<0.05$ was considered statistically significant and data analyses were conducted in Stata software version 14.0 (StataCorp LLC, College Station, Texas, USA). Currencies extracted from the included cost articles were converted into US\$ with the appropriate exchange rate for the respective cost year. Costs were adjusted for inflation by using the average consumer price index $(\mathrm{CPI})^{20}$ for each country and purchasing power parity $(\mathrm{PPP})^{21}$ for the year 2015 to enable comparability. When information for cost year was missing, the year of the data collection was as assumed to be the cost year.

\section{Results}

A total of 5,570 publications were identified, and after scanning titles/abstracts, 5,298 
publications were excluded due to not meeting the inclusion criteria (not chronic wounds, no generic HRQoL data or no cost data). After adding two articles from manual searches, 274 articles were viewed in full-text, of which 244 did not meet the inclusion criteria. Finally, 30 articles (one article presented both HRQoL and costs data) were included in the systematic review (Figure 1).

\section{Insert Figure 1 here}

In the included articles, 16 labelled the wound as chronic or hard-to-heal, and five studies stated a wound duration longer than three weeks, but did not label the wounds chronic/hard-to-heal. Eight studies assessed amputations, and one study presented both chronic wounds and amputations.

The majority of the included HRQoL articles $(n=17)$ presented acceptable sample sizes for HRQoL studies. ${ }^{22}$ However, methods for sampling were often based on convenience or poorly described. Seven articles had appropriate sampling methods and most studies $(n=18)$ described study participants and settings in detail, and measured HRQoL by validated methods. With regards to the Drummond and Jefferson's Checklist, several non-applicable items for cost-ofillness evaluations were excluded in the quality assessment. All included cost studies stated the research question $(n=11)$, most studies presented the economic importance of the study $(n=10)$, few studies presented details of study participants $(n=3)$, and only one study discussed the productivity impact. More than half of the studies presented the quantity of resource use separated from the unit costs $(n=7)$, most studies provided currency and price data $(n=9)$, and approximately half of the studies presented details of currency and price adjustments for inflation 
conversions $(\mathrm{n}=5)$. Eight studies stated a time horizon for costs, one study incorporated discounting, and no study justified the choice of discount rate nor gave an explanation for nondiscounted costs. A sensitivity analysis was presented in only one study. The majority of studies answered their research question $(\mathrm{n}=10)$ and all studies provided a conclusion.

Insert Table 1 here

The HRQoL articles consisted of nine cross-sectional studies, six case-control studies, two observational studies, one quasi-experimental study, and one study assessed a measurement tool for HRQoL and one pilot study. Two studies (using SF-36 and EQ-5D) failed to report standardised domain scores which impeded comparability to other studies applying the same instrument. $^{23,24}$ In one study, only wound duration specific subgroup data could be extracted due to lack of chronicity information for the rest of the sample (mixed wounds of unknown duration). ${ }^{25}$

Nine different instruments were used to measure HRQoL (five studies used more than one instrument). SF-36, the most frequently used instrument was used in half of the studies. Six studies presented aggregated utility values from different HRQoL instruments; Nottingham Health Profile (NHP), ${ }^{26}$ SF-36, ${ }^{25}$ EQ-5D,${ }^{27}$ Ferran's and Power's Quality of Life Index (QLI), ${ }^{28}$ EQ-5D Visual Analogue Scale (VAS), ${ }^{27,}{ }^{29}$ WHOQOL-bref., ${ }^{30}$ and Numerical Rating Scale (NRS). ${ }^{27}$ One study evaluated a disease specific instrument for patients with chronic wounds by comparing domain scores from three different HRQOL tools. ${ }^{27}$

Patients with chronic wounds most frequently reported lower HRQoL scores in the domains related to physical pathologies i.e. role physical, physical functioning, equivalent to mobility 
and/or the physical summary component (PSC). ${ }^{26,31-40}$ The similar and comparable domains, vitality (SF-36) and energy (NHP) ${ }^{32}$, also presented inferior scores for patients with chronic wounds. ${ }^{26,34,35,39,41}$ For emotional- and mental health domains, four studies reported lower HRQoL scores for patients with chronic wounds, ${ }^{31,35,36,40}$ while five studies did not find any statistical difference when compared to controls. ${ }^{34,37-39,42}$ Four studies with control groups reported significantly lower scores for patients with chronic wounds in the domains of bodily pain and pain/discomfort. ${ }^{26,35,39,40}$ Eight studies were homogenous enough to enable calculations of pooled estimates of HRQoL for patients with chronic wounds and amputations (Table 2)). ${ }^{33-36 \text {, }}$ 39-41, 43 The estimates showed that patients with amputation had inferior scores in most domains, except for the domain role physical, pain and social function where patients with chronic wounds had lower scores. Further, in the subgroup analysis, five studies incorporated patients with chronic wounds and control groups. The box plots $(n=5$ showed lower mean scores for chronic wound patients in all SF-36 domains when compared to the control groups. (Supplementary Figure 1). However, these scores should be interpreted with caution due to small sample sizes, large differences in study designs, and heterogeneity in participant characteristics.

\section{Insert Table 2 here}

Insert Figure 2 here

Long wound duration and/or large wound size were correlated to poorer HRQoL scores in three studies. ${ }^{25,37,40}$ Three studies specifically assessed pain and HRQoL for patients with chronic wounds, and showed that patients with chronic wounds and severe pain reported even lower HRQoL in several domains compared to patients with wounds experiencing less pain. ${ }^{24,30,31}$ One 
study compared patients with amputation and patients with chronic wounds, with significantly poorer scores in the domain bodily pain presented for the latter. ${ }^{33}$ An association between pain and lower HRQoL was also supported by two other studies reporting improvements in the domain bodily pain and subsequent increases in overall HRQoL after wound healing for patients with chronic wounds. ${ }^{29,40}$

None of the included HRQoL studies addressed or assessed the caregivers' perspective and their HRQoL.

Insert Table 3 here

Eleven cost-of-illness studies assessing patients with chronic wounds were found for the cost data. Participants were identified through hospital- and patient records, Diagnosis Related Group (DRG) codes, International Classification of Diseases (ICD) codes, health insurance companies, wound clinics and national disease specific registers. The study settings captured costs from inpatient, outpatient, community and primary care perspectives e.g. hospitals, wound centres and foot care teams. ${ }^{44-46}$ Cost data in this section were converted into annual costs when possible to enable a better overview.

Diabetes related amputations reported the largest proportion of costs for chronic wounds, ${ }^{38,45,47}$, ${ }^{48}$ a cost largely associated with additional inpatient days when hospitalised compared to nondiabetic patients. ${ }^{45,48}$ Cost for hospitalisation for diabetes related amputations ranged from US\$ $12 \cdot 851^{49}$ to $16 \cdot 267^{47}$ (median) per patient admitted. Davis et al. ${ }^{49}$ estimated that $9 \cdot 3 \%$ of the total cost for diabetes-related hospital admissions was related to amputations. One study presented diabetes related amputation costs from a societal perspective, including both direct- and indirect 
costs, estimated at US\$ 33.499 in year 2002 (total annual cost per patient) ${ }^{38}$ Long treatment times after amputation e.g. rehabilitation, outpatient costs and other additional long-term care also contributed to substantial costs related to amputations. ${ }^{38,48}$

Cost for leg ulcers were assessed in five studies in primary care, outpatient and community settings (one study covered both in- and outpatient settings). Leg ulcers presented considerably lower costs than amputations, with costs that ranged from US\$ $449^{50}$ to $2 \cdot 307^{51}$ annually per patient for primary- and outpatient care, and between US\$ $13 \cdot 334^{46}$ and $13 \cdot 761^{44}$ from a societal perspective. Wound treatment costs (e.g. medical equipment and consumables) were considerable for chronic wound management across all study settings. ${ }^{38,44,48,50}$ One study compared wound treatment costs for in- and outpatients in hospital settings, and reported no difference for the cost for wound treatment, but detected a lower cost for consumables for the non-hospitalized patients. ${ }^{52}$ Large ulcer size, and more severe ulceration ${ }^{38,44,50}$ with subsequent longer treatment duration (>6 months) (nurse visits for wound dressings and drug prescriptions from physicians, e.g. analgesics and antibiotics), ${ }^{44,50,51}$ were associated with higher costs. Two studies presented more than doubled costs for patients having larger and more than one wound, when compared to smaller ulcers with shorter healing times. ${ }^{44,50}$ Having several chronic wounds was found to be more cost enlarging due to longer work time for nurses and the utilisation of more wound care products. ${ }^{38,44}$ Pain severity was another cost-contributing factor related to an increased consumption of analgesics for pain management. ${ }^{46}$ One large study assessing costs for chronic wounds from a Medicaid service claim database concluded that hospitalisation made up the larger proportion compared to physician visits and prescription costs. ${ }^{53}$ Three studies assessed indirect costs, ${ }^{38,44,46}$ and reported costs for early retirement, ${ }^{38,44}$ temporary work disability, ${ }^{38,44}$ and productivity losses due to wound dressings (but failed to 
describe how this was assessed). ${ }^{46}$ The latter study also assessed but did not calculate or report costs for the patients' productivity losses since "only a few participants in the study were still working", 46

\section{Discussion}

This systematic review attempted to have a clear definition for chronicity of wounds even though there is no pre-established consensus, to ensure the inclusion of only chronic wounds. The review reveals a poorer HRQoL for patients with chronic wounds, and that wound related costs are considerable. The inferior HRQoL observed for patients with chronic wounds is worst for physical pathologies, and are similar or markedly lower in some domains when compared to HRQoL for other chronic conditions e.g. chronic obstructive pulmonary disease and cardiovascular diseases. ${ }^{54,55}$ Pain and reduced mobility were reported as the main problem areas for patients with wounds, which underlines the urgent need for improvements in those domains to alleviate the most negative impacts of the condition. ${ }^{56}$ It should also be noted that HRQoL may differ between participants due to what wound treatment patients received, if any additional complications were present as well as the current stage of the wound healing trajectory. For example, decreases in HRQoL are often associated with an advancement in the severity of the wound. $^{38}$

No publication assessing HRQoL for informal caregivers of patients with chronic wounds was identified in the review, impeding a more comprehensive exploration of the humanistic and economic burden of chronic wounds.

For costs, diabetes related amputations presented the greatest costs. These were attributed to lengthy hospital stays and long-term costs e.g. rehabilitation and outpatient treatments. In 
comparison to patients admitted for heart failure, the median cost per hospitalisation were larger for diabetes related amputations (US\$12,851 to 16,267 vs. US\$ 10,454 for heart failure), ${ }^{57}$ indicating that amputation costs are similar to other major public health scourges. The substantial cost for diabetes related amputations shows the importance of preventing chronic wounds from developing into a severe state where amputation is unavoidable. Previous research suggests that cost-saving preventions for amputations should be early and incorporate a comprehensive wound management strategy. ${ }^{58}$ Appropriate interventions and management for wounds can lower the risk of amputation by $47 \%$ to $72 \%$ depending on strategy (e.g. education, multidisciplinary approaches, wound monitoring, vascular surgery interventions, and the use of therapeutic foot wear) ${ }^{58-60}$ with cost reductions from US $\$ 85,000$ up to $1,100,000$ per year and intervention. ${ }^{59}$ The review revealed that costs for leg ulcers were lower than for amputations and predominantly related to community- and primary care. Although presenting lower costs than amputations, the cost for leg ulcers will accelerate when wounds persist for many years. The work time of nurses and costs for dressing materials are considered the main cost causative components for leg ulcers, which suggests that reduced working time and dressing frequencies would lower costs for leg ulcers. ${ }^{61}$ This could be achieved by early detection of changes in the wound that result in worsening conditions, and subsequently providing prompt treatment before the wound requires more extensive care. ${ }^{58}$ To enable timely identification of such changes in wounds, extended wound monitoring is fundamental, while to avoid adding costs for nurses work time, technology based interventions such as tele monitoring could be a solution. ${ }^{62}$ Other preventive and costeffective treatments for leg ulcers when the underlying cause is venous insufficiency are compression therapies ${ }^{63,64}$ and vascular surgery. ${ }^{64}$

Few articles in the current review addressed indirect costs. A plausible reason for this might be 
that chronic wounds often occur in patients above retirement ages. ${ }^{44}$ However, a previous study reported substantial indirect costs related to work absenteeism among patients with wounds. ${ }^{65}$ Hence, capturing indirect costs are important to comprehensively assess the economic burden of chronic wounds.

Several studies assessed for eligibility in the review failed to specify wound chronicity and were therefore excluded, e.g. pressure ulcers were only labelled as: chronic" in one of the included articles since this wound type is more commonly is referred to in terms of stages of tissue loss. Introducing a specified duration/label for inclusion may have excluded relevant articles, but at the same time this approach ensured that included article were in fact focused on chronic wounds, which adds to the robustness of the findings. Including only articles in English, as well as the overrepresentation of articles from European countries, may have resulted in a reduced generalizability of the findings. Characteristics of study populations were not always clearly stated which is an important aspect given that the patients often were recruited from rather homogenous settings e.g. clinics, hospitals which also affects the generalizability. Furthermore, the participants were predominantly over 60 years of age, which possibly caused a lower HRQoL related to decreased mobility and increased probability of being comorbid in older ages. However, the risk of developing chronic ulcers increases with age hence reflects the target study population.

For the economic burden of leg ulcers, comparing costs for ulcers of vascular and arterial aetiologies would have been valuable, but no cost study differentiated between ulcers of vascular and arterial aetiologies, prohibiting comparisons.

Large variations across the studies collecting data for HRQoL (different instruments used) and variations in the costs being assessed impeded larger scale pooled estimates for HRQoL and 
feasible cost comparisons. It can be argued that including only generic HRQoL into this systematic review may have captured the impact of chronic wounds on HRQoL less adequately due to common comorbidities in this patient population. ${ }^{66}$ However, information on HRQoL based on data collected by condition-specific tools prevents comparisons of HRQoL across diseases which is important for decisions that concern resource allocation. ${ }^{66}$

Methodological discrepancies for cost articles comprised wounds of various aetiology and severity levels being assessed (with subsequently different treatments), further complicated by assorted cost categories and cost-perspectives being applied. Inconsistency of evidence can also be attributed to the lack of sensitivity analyses to account for the degree of uncertainty of cost valuations (only conducted in one study), lack of presentation of detailed cost data, variation in study design and valuations of unit costs as well as costs being reported from different healthcare systems in various countries making it difficult to conduct feasible cost comparisons. For example, multiple studies did not present the sources of where data for unit costs were retrieved, and some studies assumed that all health care utilisation was related to the wound treatment. This is most likely not the case since participants may suffer from other comorbidities. Moreover,

most studies presented patients with chronic wounds without a comparison group, thus making it difficult to understand the burden of chronic wounds in relation to healthy individuals and other patient groups.

In conclusion, patients with chronic wounds report low HRQoL and the condition imposes a substantial economic burden. To improve HRQoL and reduce costs for this patient group, better wound care management must be implemented. This study also detected a lack of published HRQoL data for the caregivers of patients with chronic wounds, and notes that only a few cost studies included indirect costs. Future studies need to assess HRQoL of informal caregivers and 
capture productivity losses for patients with chronic wounds to comprehensively estimate the economic burden from a societal perspective.

\section{Acknowledgements}

The research was supported through internal grant funding from Lee Kong Chian School of Medicine, Nanyang Technological University and A*STAR BMRC Strategic Positioning Fund (SPF) for Skin Biology (awarded to the Institute of Medical Biology). MO conducted data collection, analysed, interpreted data and drafted the manuscript. KJ conceptualized and designed the study, took part in analyses, supervised and reviewed the manuscript. DU assisted in data collection, analysis of data and reviewed the manuscript. RB took part in the study design, managed the statistical analyses and reviewed the methodology content of the manuscript. ZU and AS took part in the initial design of the study and revised the manuscript draft. JC was PI of the project and revised the manuscript. All authors contributed to and approved the final manuscript. The authors declare no conflict of interest and all authors contributed sufficiently to be credited at co-authors.

\section{Footnotes}

CINAHL Cumulative Index to Nursing and Allied Health Literature

DRG

Diagnosis Related Group

EBM

Evidence-based Medicine

EQ-5D

EuroQol-5D

EQ-5D VAS

VAS EuroQol-5D Visual Analogue Scale 
EBSCO

EMBASE

HRQOL

ICD

JBI

MEDLINE

NHP

NRS

PRISMA

PSC

QLI

SF-36

SF-12

VAS

WHOQOL-bref
EBSCO Information Services

Excerpta Medica dataBASE

Health-related quality of life

International Classification of Diseases

Joanna Briggs Institute

Medical Literature Analysis and Retrieval System Online

Nottingham Health Profile

Numerical Rating Scale

Preferred reporting items for systematic reviews and meta-analyses

Physical summary component

Ferran's and Power's Quality of Life Index

MOS 36-item Short-Form Health Survey

MOS 12-Item Short Form Survey Instrument

Visual Analogue Scale

World Health Organization Quality of Life-BREF 


\section{References}

1. Frykberg RG, Banks J. Challenges in the Treatment of Chronic Wounds. Adv Wound Care 2015; 4: 560-82.

2. Kyaw BM, Järbrink K, Martinengo L, Car J, Harding K, Schmidtchen A. Need for Improved Definition of "Chronic Wounds" in clinical studies. Acta Derm Venereol 2018; 98:157-58.

3. Walker N, Rodgers A, Birchall N, Norton R, MacMahon S. Leg ulcers in New Zealand: age at onset, recurrence and provision of care in an urban population. $N Z$ Med J 2002; 115: 286-9.

4. Kinmond K, McGee P, Gough S, Ashford R. 'Loss of self': a psychosocial study of the quality of life of adults with diabetic foot ulceration. J Tissue Viability 2003; 13: 6-16.

5. Posnett J, Franks PJ. The burden of chronic wounds in the UK. Nurs Times 2008; 104: 44-5.

6. Phillips CJ, Humphreys I, Fletcher J, Harding K, Chamberlain G, Macey S. Estimating the costs associated with the management of patients with chronic wounds using linked routine data. Int Wound J 2015.

7. Sen CK, Gordillo GM, Roy S, et al. Human skin wounds: a major and snowballing threat to public health and the economy. Wound Repair Regen 2009; 17: 763-71.

8. Guyatt GH, Feeny DH, Patrick DL. Measuring health-related quality of life. Ann Intern Med 1993; 118: 622-9.

9. Guest JF, Ayoub N, McIlwraith T, et al. Health economic burden that different wound types impose on the UK's National Health Service. Int Wound J 2017; 14: 322-30.

10. Chan B, Cadarette S, Wodchis W, Wong J, Mittmann N, Krahn M. Cost-of-illness studies in chronic ulcers: a systematic review. J Wound Care 2017; 26: 4-14.

11. Moher D, Shamseer L, Clarke M, et al. Preferred reporting items for systematic review and meta-analysis protocols (PRISMA-P) 2015 statement. Syst Rev 2015; 4: 1.

12. Järbrink K, Ni G, Sönnergren H, et al. The humanistic and economic burden of chronic wounds: a protocol for a systematic review. Syst Rev 2017; 6: 15.

13. Sheehan P, Jones P, Caselli A, Giurini JM, Veves A. Percent change in wound area of diabetic foot ulcers over a 4-week period is a robust predictor of complete healing in a 12 -week prospective trial. Diabetes care 2003; 26: 1879-82.

14. The Johanna Briggs Institute Data Extraction Form for Economic Evaluations http://joannabriggs.org/assets/docs/jbc/operations/dataExtractionForms/JBC_Form_DataE_EconEval.pdf (accessed October 26, 2016 ).

15. The Johanna Briggs Institute Checklist for Prevalence Studies 2016. http://joannabriggs.org/assets/docs/critical-appraisal-tools/JBI_Critical_Appraisal-

Checklist_for_Prevalence_Studies.pdf (accessed November 8 2016).

16. Munn Z, Moola S, Riitano D, Lisy K. The development of a critical appraisal tool for use in systematic reviews addressing questions of prevalence. Int J Health Policy Manag 2014; 3: 123-8.

Drummond MF, Jefferson TO. Guidelines for authors and peer reviewers of economic submissions to the BMJ. The BMJ Economic Evaluation Working Party. Bmj 1996; 313: 275-83.

18. Fu R, Vandermeer BW, Shamliyan TA, et al. Handling Continuous Outcomes in Quantitative Synthesis. Methods Guide for Comparative Effectiveness Reviews. Agency for Healthcare Research and Quality, 2013. https://www.ncbi.nlm.nih.gov/books/NBK154408/pdf/Bookshelf_NBK154408.pdf (accessed 15 April 2017).

19. Higgins JPT, Green S. Cochrane Handbook for Systematic Reviews of Interventions Version 5.1.0 [updated March 2011]. The Cochrane Collaboration, 2011. http://handbook.cochrane.org (accessed April 12, 2017)

20. OECD Statistics. Consumer prices (MEI). http://stats.oecd.org/Index.aspx?querytype=view\&queryname=221 (accessed 4 October 2016).

21. OECD Statistics. Purchasing Power Parities (PPP) for GDP and exchange rates. https://stats.oecd.org/Index.aspx?DataSetCode=SNA_TABLE4 (accessed 4 October 2016).

22. Julious SA, George S, Campbell MJ. Sample sizes for studies using the short form 36 (SF-36). J Epidemiol Community Health 1995; 49: 642-644.

23. Willrich A, Pinzur M, McNeil M, Juknelis D, Lavery L. Health related quality of life, cognitive function, and depression in diabetic patients with foot ulcer or amputation. A preliminary study. Foot Ankle Int 2005; 26: 128-34.

24. Renner R, Seikowski K, Simon JC. Association of pain level, health and wound status in patients with chronic leg ulcers. Acta Derm Venereol 2014; 94: 50-3. 
25. Garcia-Morales E, Lazaro-Martinez JL, Martinez-Hernandez D, Aragon-Sanchez J, Beneit-Montesinos JV, Gonzalez-Jurado MA. Impact of diabetic foot related complications on the Health Related Quality of Life (HRQol) of patients-a regional study in Spain. Int J Low Extrem Wounds 2011; 10: 6-11.

26. Moffatt CJ, Franks PJ, Doherty DC, Smithdale R, Steptoe A. Psychological factors in leg ulceration: a case-control study. Br J Dermatol 2009; 161: 750-6.

27. Blome C, Baade K, Sebastian Debus E, Price P, Augustin M. The ' Wound- QoL': A short questionnaire measuring quality of life in patients with chronic wounds based on three established disease-specific instruments. Wound Repair Regen 2014; 2: 504-14.

28. Yamada BFA, de Gouveia Santos VLC. Quality of life of individuals with chronic venous ulcers. Wounds 2005; 17: 178-89.

29. Oien RF, Akesson N, Forssell H. Assessing quality of life in patients with hard-to-heal ulcers using the EQ5D questionnaire. J Wound Care 2013; 22: 442-4, 6-7.

30. Park SH, Ferreira K, Santos VL. Understanding pain and quality of life for patients with chronic venous ulcers. Wounds 2008; 20: 309-20.

31. Guarnera G, Tinelli G, Abeni D, Di Pietro C, Sampogna F, Tabolli S. Pain and quality of life in patients with vascular leg ulcers: an Italian multicentre study. J Wound Care 2007; 16: 347-51.

32. Kristofferzon ML, Ternesten-Hasseus E. A study of two generic health-related quality of life questionnaires--Nottingham Health Profile and Short-Form 36 Health Survey--and of coping in patients with sensory hyperreactivity. Health Qual Life Outcomes 2013; 11: 182.

33. Boutoille D, Feraille A, Maulaz D, Krempf M. Quality of life with diabetes-associated foot complications: comparison between lower-limb amputation and chronic foot ulceration. Foot Ankle Int 2008; 29: $1074-8$.

34. Chase SK, Whittemore R, Crosby N, Freney D, Howes P, Phillips TJ. Living with chronic venous leg ulcers: A descriptive study of knowledge and functional health status. J Community Health Nurs 2000; 17: $1-13$.

35. Faria E, Blanes L, Hochman B, Mesquita Filho M, Ferreira L. Health-related quality of life, self-esteem, and functional status of patients with leg ulcers. Wounds 2011; 23: 4-10.

36. Jull A, Walker N, Hackett M, et al. Leg ulceration and perceived health: a population based case-control study. Age Ageing 2004; 33: 236-41.

37. Goodridge D, Trepman E, Sloan J, et al. Quality of life of adults with unhealed and healed diabetic foot ulcers. Foot Ankle Int 2006; 27: 274-80.

38. Happich M, John J, Stamenitis S, Clouth J, Polnau D. The quality of life and economic burden of neuropathy in diabetic patients in Germany in 2002 - results from the Diabetic Microvascular Complications (DIMICO) study. Diabetes Res Clin Pract 2008; 81: 223-30.

39. Alzahrani HA, Sehlo MG. The impact of religious connectedness on health-related quality of life in patients with diabetic foot ulcers. J Relig Health 2013; 52: 840-50.

Franks PJ, McCullagh L, Moffatt CJ. Assessing quality of life in patients with chronic leg ulceration using the Medical Outcomes Short Form-36 questionnaire. Ostomy Wound Manag 2003; 49: 26-37.

41. de Souza DMST, Borges FR, Juliano Y, Veiga DF, Ferreira LM. Quality of life and self-esteem of patients with chronic ulcers. Acta Paulista de Enfermagem 2013; 26: 283-8.

42. McDonald S, Sharpe L, Blaszczynski A. The psychosocial impact associated with diabetes-related amputation. Diabet Med 2014; 31: 1424-30.

43. Ribu L, Hanestad BR, Moum T, Birkeland K, Rustoen T. Health-related quality of life among patients with diabetes and foot ulcers: association with demographic and clinical characteristics. J Diabetes

Complications 2007; 21: 227-36.

44. Purwins S, Herberger K, Debus ES, et al. Cost-of-illness of chronic leg ulcers in Germany. Int Wound J 2010; 7: 97-102.

45. Tennvall GR, Apelqvist J, Eneroth M. Costs of deep foot infections in patients with diabetes mellitus. Pharmacoeconomics 2000; 18: 225-38.

46. Augustin M, Brocatti LK, Rustenbach SJ, Schafer I, Herberger K. Cost-of-illness of leg ulcers in the community. Int Wound J 2014; 11: 283-92.

47. Alzahrani HA. The direct cost of diabetic foot management in some of private hospitals in Jeddah, Saudi Arabia. Int J Diabetes in Dev Ctries 2013; 33: 34-9.

48. Hoffmann F, Claessen H, Morbach S, Waldeyer R, Glaeske G, Icks A. Impact of diabetes on costs before and after major lower extremity amputations in Germany. J Diabetes Complications 2013; 27: 467-72. 
49. Davis WA, Norman PE, Bruce DG, Davis TM. Predictors, consequences and costs of diabetes-related lower extremity amputation complicating type 2 diabetes: the Fremantle Diabetes Study. Diabetologia 2006; 49: 2634-41.

50. Tennvall GR, Hjelmgren J, Öien R. The cost of treating hard-to-heal venous leg ulcers: results from a Swedish survey. World Wide Wounds 2006. www.worldwidewounds.com/2006/november/Tennvall/Costof-treating-hard-to-healvenous-

leg-ulcers.html (accessed December 20, 2017).

51. Muller-Buhl U, Leutgeb R, Bungartz J, Szecsenyi J, Laux G. Expenditure of chronic venous leg ulcer management in German primary care: results from a population-based study. Int Wound J 2013; 10: 52-6.

52. Assadian O, Oswald JS, Leisten R, Hinz P, Daeschlein G, Kramer A. Management of leg and pressure ulcer in hospitalized patients: direct costs are lower than expected. GMS Krankenhaushygiene Interdisziplinaer 2011; 6: 1-7.

53. Kumar RN, Gupchup GV, Dodd MA, et al. Direct health care costs of 4 common skin ulcers in New Mexico Medicaid fee-for-service patients. Adv Wound Care 2004; 17: 143-9.

54. Martín A, Moro JMR-G, Izquierdo JL, Gobartt E, de Lucas P. Health-related quality of life in outpatients with COPD in daily practice: the VICE Spanish Study. Int J Chron Obstruc Pulmon Dis 2008; 3: 683.

55. Juenger J, Schellberg D, Kraemer S, et al. Health related quality of life in patients with congestive heart failure: comparison with other chronic diseases and relation to functional variables. Heart 2002; 87: 23541.

56. Corbett LQ, Ennis WJ. What Do Patients Want? Patient Preference in Wound Care. Adv Wound Care (New Rochelle) 2014; 3: 537-43.

57. Titler MG, Jensen GA, Dochterman JM, et al. Cost of hospital care for older adults with heart failure: medical, pharmaceutical, and nursing costs. Health Serv Res 2008; 43: 635-55.

58. Yazdanpanah L, Nasiri M, Adarvishi S. Literature review on the management of diabetic foot ulcer. World J Diabetes 2015; 6: 37-53.

59. Driver VR, Fabbi M, Lavery LA, Gibbons G. The costs of diabetic foot: the economic case for the limb salvage team. J Vasc Surg 2010; 52: 17-22.

60. Tan ML, Feng J, Gordois A, Wong ES. Lower extremity amputation prevention in Singapore: economic analysis of results. Singapore Med J 2011; 52: 662-8.

61. Nelzen O. Leg ulcers: economic aspects. Phlebology 2000; 15: 110-4.

62. Hofmann-Wellenhof R, Salmhofer W, Binder B, Okcu A, Kerl H, Soyer HP. Feasibility and acceptance of telemedicine for wound care in patients with chronic leg ulcers. J Telemed Telecare 2006; 12: 15-7.

63. Marston WA, Carlin RE, Passman MA, Farber MA, Keagy BA. Healing rates and cost efficacy of outpatient compression treatment for leg ulcers associated with venous insufficiency. J Vasc Surg 1999; 30: 491-8.

64. Adeyi A, Muzerengi S, Adeyi IGA, Gupta I. Leg Ulcers In Older People: A Review Of Management Leg Ulcers In Older People: A Review Of Management. Br J Med Pract 2009; 2.

65. Tan B, Tan E, Chong S, Chang Y, Song C, Lee V. An economic evaluation of chronic wound management in a tertiary hospital. Wounds Australia 2016; 24: 130.

66. Price P, Krasner DL. Health-related quality of life and chronic wounds: evidence and implications for practice: In Krasner DL, Rodeheaver GT, Sibbald RG, Woo KY, eds. Chronic Wound Care: A Clinical Source Book for Healthcare Professionals. Vol. 1. $5^{\text {th }}$ ed. Malvern, PA: HMP Communications; 2012. 
Figure 1. Flow chart of study selection

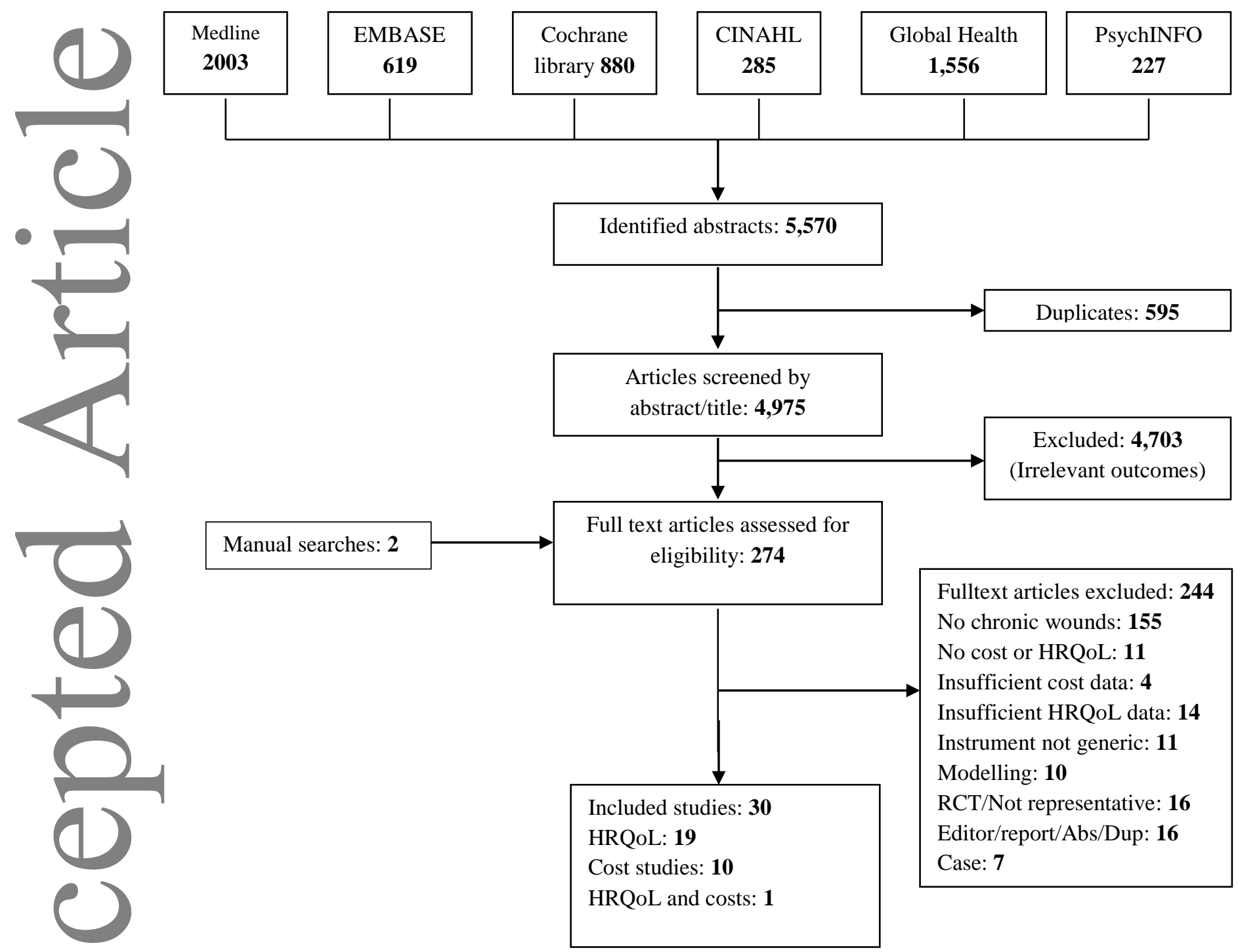


Figure 2. Average scores with 95\% confidence intervals for the eight domains of SF-36

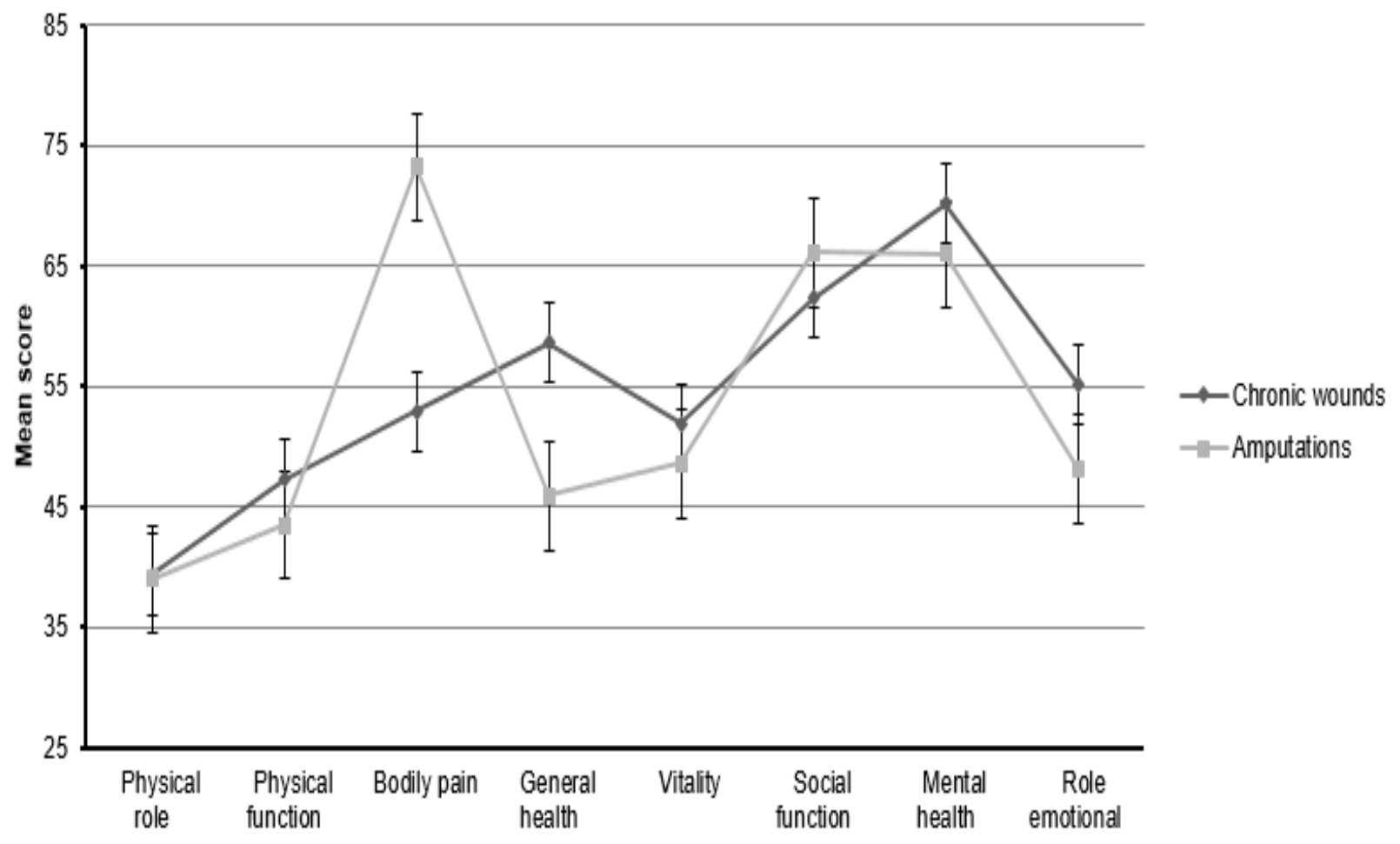

Table 1. Characteristics of the included HRQoL studies presented by wound type ( $\mathrm{n}=20)$

\begin{tabular}{|l|l|l|l|l|l|l|}
\hline Reference & Countr & Type of & Setting & No. & Ag & HRQoL \\
& $y$ & wound & & of & e & instrument \\
& & & & pati & (m & \\
& & & & ent & ea & \\
\hline
\end{tabular}




\begin{tabular}{|c|c|c|c|c|c|c|}
\hline & & & & $\mathbf{S}$ & n) & \\
\hline $\begin{array}{l}\text { Blome et al. } \\
2014^{\frac{27}{}}\end{array}$ & $\begin{array}{l}\text { German } \\
\mathrm{y}\end{array}$ & Leg ulcer & Wound care clinic, hospital vascular unit & 154 & 65 & $\begin{array}{l}\text { EQ-5D, EQ- } \\
\text { 5D VAS, } \\
\text { NRS }\end{array}$ \\
\hline $\begin{array}{l}\text { Renner et al. } \\
2014^{24}\end{array}$ & $\begin{array}{l}\text { German } \\
\mathrm{y}\end{array}$ & Leg ulcer & Outpatient wound clinic & 103 & 68 & EQ-5D \\
\hline $\begin{array}{l}\text { Faria et al. } \\
2011^{\underline{35}}\end{array}$ & Brazil & Leg ulcer & $\begin{array}{l}\text { Hospital, outpatient clinics, family health } \\
\text { clinic }\end{array}$ & 80 & 64 & SF-36 \\
\hline $\begin{array}{l}\text { Moffatt et al. } \\
2009^{26}\end{array}$ & $\begin{array}{l}\text { United } \\
\text { Kingdo } \\
\text { m }\end{array}$ & Leg ulcer & Acute and community leg ulcer service & 95 & $\begin{array}{c}59 \\
\% \\
\geq 7 \\
5\end{array}$ & NHP \\
\hline $\begin{array}{l}\text { Park et al. } \\
2008^{\underline{30}}\end{array}$ & Brazil & Leg ulcer & Outpatient clinic & 40 & 68 & $\begin{array}{l}\text { WHOQL- } \\
\text { bref + PI- } \\
\text { NRS }\end{array}$ \\
\hline $\begin{array}{l}\text { Guarnera et } \\
\text { al. } 2007^{31}\end{array}$ & Italy & Leg ulcer & $\begin{array}{l}\text { Outpatient vascular surgery and angiology } \\
\text { unit }\end{array}$ & 381 & $*$ & $\begin{array}{c}\text { SF-12+ } \\
\text { VAS }\end{array}$ \\
\hline $\begin{array}{l}\text { Yamada et al. } \\
2005^{\underline{28}}\end{array}$ & Brazil & Leg ulcer & Vascular surgery outpatient clinics & 89 & 53 & $\begin{array}{l}\text { Ferran's and } \\
\text { Power's QLI }\end{array}$ \\
\hline $\begin{array}{l}\text { Jull et al. } \\
2004^{\underline{36}}\end{array}$ & $\begin{array}{l}\text { New } \\
\text { Zealand }\end{array}$ & Leg ulcer & Population based & 230 & 75 & SF-36 \\
\hline $\begin{array}{l}\text { Franks et al. } \\
2003^{40}\end{array}$ & $\begin{array}{l}\text { United } \\
\text { Kingdo } \\
\text { m }\end{array}$ & Leg ulcer & $\begin{array}{l}\text { Community (general practice, community } \\
\text { nurses and hospital services in and out- } \\
\text { patient) }\end{array}$ & 118 & 78 & SF-36 \\
\hline
\end{tabular}




\begin{tabular}{|c|c|c|c|c|c|c|}
\hline $\begin{array}{l}\text { Chase et al. } \\
2000^{34}\end{array}$ & $\begin{array}{l}\text { United } \\
\text { States }\end{array}$ & Leg ulcer & Outpatient clinics & 21 & 72 & SF-36 \\
\hline $\begin{array}{l}\text { McDonald et } \\
\text { al. } 2014^{42}\end{array}$ & $\begin{array}{l}\text { Australi } \\
\text { a }\end{array}$ & $\begin{array}{l}\text { Diabetes } \\
\text { amputation }\end{array}$ & $\begin{array}{l}\text { Diabetes and amputee member's } \\
\text { association in Sydney }\end{array}$ & 50 & 63 & $\begin{array}{l}\text { WHOQOL- } \\
\text { bref }\end{array}$ \\
\hline $\begin{array}{l}\text { Happich et al. } \\
2008^{38}\end{array}$ & $\begin{array}{l}\text { German } \\
\mathrm{y}\end{array}$ & $\begin{array}{l}\text { Diabetes } \\
\text { amputation }\end{array}$ & Multicentre & 71 & $\begin{array}{l}67 / \\
68\end{array}$ & SF-12 \\
\hline $\begin{array}{l}\text { Ribu et al. } \\
2007^{\frac{43}{3}}\end{array}$ & Norway & $\begin{array}{l}\text { Diabetes } \\
\text { amputation }\end{array}$ & Outpatient clinics & 26 & 60 & SF-36 \\
\hline $\begin{array}{l}\text { Willrich et al. } \\
2005^{\frac{23}{3}}\end{array}$ & USA & $\begin{array}{l}\text { Diabetes } \\
\text { amputation }\end{array}$ & Hospital rehabilitation centre & 20 & $*$ & SF-36 \\
\hline $\begin{array}{l}\text { Boutoille et } \\
\text { al. } 2008^{\frac{33}{3}}\end{array}$ & France & $\begin{array}{l}\text { Diabetes } \\
\text { amputation } \\
\text { Diabetic foot } \\
\text { ulcer }\end{array}$ & $\begin{array}{l}\text { Patients living at home one year after } \\
\text { amputation } \\
\text { Outpatients receiving regular care for } \\
\text { diabetic foot ulcers }\end{array}$ & 25 & $\begin{array}{l}68 \\
\\
70\end{array}$ & SF-36 \\
\hline $\begin{array}{l}\text { Alzahrani } \\
2013^{\frac{39}{2}}\end{array}$ & $\begin{array}{l}\text { Saudi } \\
\text { Arabia }\end{array}$ & $\begin{array}{l}\text { Diabetic foot } \\
\text { ulcer }\end{array}$ & Outpatient diabetic foot clinic & 60 & 57 & SF-36 \\
\hline $\begin{array}{l}\text { Garcia- } \\
\text { Morales et al. } \\
2011^{25}\end{array}$ & Spain & $\begin{array}{l}\text { Diabetic foot } \\
\text { ulcer }\end{array}$ & Diabetic foot ulcer unit & 163 & 62 & SF-36 \\
\hline $\begin{array}{l}\text { Goodridge et } \\
\text { al. } 2006^{\frac{37}{}}\end{array}$ & Canada & $\begin{array}{l}\text { Diabetic foot } \\
\text { ulcer }\end{array}$ & Hospital/diabetic foot ulcer clinic & 57 & $64^{\mathrm{a}}$ & SF-12 \\
\hline
\end{tabular}




\begin{tabular}{|l|l|l|l|l|l|l|}
\hline de Souza et & Brazil & Ulcers of & Hospital and outpatient clinic & & \\
mixed & & & & \\
& & aetiologies & & & \\
\hline Oien et al. & Sweden & Ulcers of & Primary care wound clinic & & \\
$2013^{29}$ & & mixed & & 50 & $79^{\text {b }}$ & EQ-5D, EQ- \\
& & aetiologies & & 5 VAS \\
\hline
\end{tabular}

* Age was not reported or reported in an incomprehensive manner

${ }^{\text {a }}$ Mean age for the whole sample also consisting of healed wounds

${ }^{\mathrm{b}}$ Presented as median

EQ-5D

EQ-5D

VAS

NRS

NHP

SF-36

SF-12

Ferran's and Power's QLI

WHOQOL-bref
EuroQol-5D

VAS EuroQol-5D Visual Analogue Scale

Visual Analogue Scale

Numerical Rating Scale

Nottingham Health Profile

MOS 36-item Short-Form Health Survey

MOS 12-Item Short Form Survey Instrument

Ferrans and Powers Quality of Life Index

WHO Quality of Life-BREF

Table 2. Details of extracted SF-36 domain scores $(n=8)$

\begin{tabular}{|c|c|c|c|c|c|c|c|c|c|c|}
\hline \multirow[b]{2}{*}{$\begin{array}{l}\text { Referen } \\
\text { ce }\end{array}$} & \multirow[b]{2}{*}{ Group } & \multirow[b]{2}{*}{$\mathbf{N}$} & \multicolumn{8}{|c|}{ SF-36 domain scores, mean (SD) } \\
\hline & & & $\begin{array}{c}\text { Physica } \\
\text { I role }\end{array}$ & $\begin{array}{c}\text { Physica } \\
\text { I } \\
\text { functio } \\
\text { n }\end{array}$ & $\begin{array}{c}\text { Bodily } \\
\text { pain }\end{array}$ & $\begin{array}{c}\text { General } \\
\text { health }\end{array}$ & Vitality & $\begin{array}{l}\text { Social } \\
\text { function }\end{array}$ & $\begin{array}{l}\text { Mental } \\
\text { health }\end{array}$ & $\begin{array}{c}\text { Role } \\
\text { emotion } \\
\text { al }\end{array}$ \\
\hline \multirow{3}{*}{$\begin{array}{l}\text { Alzahra } \\
\text { ni } 2013\end{array}$} & $\begin{array}{l}\text { Chronic } \\
\text { wounds }\end{array}$ & 60 & $\begin{array}{l}32,13 \\
(5,4)\end{array}$ & $\begin{array}{l}38,97 \\
(5,6)\end{array}$ & $\begin{array}{l}31,53 \\
(7,1)\end{array}$ & $\begin{array}{l}30,95 \\
(4,3)\end{array}$ & $\begin{array}{l}33,72 \\
(5,6)\end{array}$ & $\begin{array}{l}43,59 \\
(11,6)\end{array}$ & $\begin{array}{l}69,21 \\
(5,7)\end{array}$ & $\begin{array}{l}57,11 \\
(61)\end{array}$ \\
\hline & Control DM & 60 & $\begin{array}{l}71,73 \\
(1,8)\end{array}$ & $\begin{array}{l}75,10 \\
(2,1)\end{array}$ & $\begin{array}{l}68,25 \\
(11,1)\end{array}$ & $\begin{array}{l}67,63 \\
(3,6)\end{array}$ & $\begin{array}{l}68,61 \\
(3,2)\end{array}$ & $\begin{array}{l}75,12 \\
(12,07)\end{array}$ & $\begin{array}{l}77,60 \\
(7,8)\end{array}$ & $\begin{array}{l}78,87 \\
(8,9)\end{array}$ \\
\hline & $\begin{array}{l}\text { Control } \\
\text { healthy }\end{array}$ & 60 & $\begin{array}{l}81,25 \\
(2,7)\end{array}$ & $\begin{array}{l}84,75 \\
(4,4)\end{array}$ & $\begin{array}{r}85,03 \\
(3,6)\end{array}$ & $\begin{array}{l}76,02 \\
(1,8)\end{array}$ & $\begin{array}{l}75,67 \\
(2,6)\end{array}$ & $\begin{array}{l}83,68 \\
(3,6)\end{array}$ & $\begin{array}{r}84,43 \\
(3,2)\end{array}$ & $\begin{array}{l}85,65 \\
(4,06)\end{array}$ \\
\hline $\begin{array}{l}\text { Boutoill } \\
\text { e } 2008\end{array}$ & $\begin{array}{l}\text { Chronic } \\
\text { wounds }\end{array}$ & 9 & $25(28)$ & $62(18)$ & $33(17)$ & $35(18)$ & $59(14)$ & $53(19)$ & $62(9)$ & $63(42)$ \\
\hline
\end{tabular}




\begin{tabular}{|c|c|c|c|c|c|c|c|c|c|c|}
\hline \multirow[t]{2}{*}{$\begin{array}{l}\text { (Median } \\
\text { ) }\end{array}$} & $\begin{array}{l}\text { Minor } \\
\text { amputations }\end{array}$ & 19 & $58(39)$ & $55(29)$ & $75(26)$ & 39 (18) & $46(20)$ & $69(26)$ & $61(19)$ & $61(46)$ \\
\hline & $\begin{array}{l}\text { Major } \\
\text { amputations }\end{array}$ & 6 & $33(34)$ & 35 (39) & $84(20)$ & $54(20)$ & $55(22)$ & $62(25)$ & $65(21)$ & $33(42)$ \\
\hline $\begin{array}{l}\text { Chase } \\
2000\end{array}$ & $\begin{array}{l}\text { Chronic } \\
\text { wounds }\end{array}$ & 21 & 67,9 & 56,2 & 75,5 & 72,7 & 50 & 83,9 & 80 & 81 \\
\hline \multirow{2}{*}{$\begin{array}{l}\text { Faria } \\
2011\end{array}$} & $\begin{array}{l}\text { Chronic } \\
\text { wounds }\end{array}$ & 80 & 22,5 & 48,68 & 57,81 & 66,18 & 59,37 & 56,25 & 64,9 & 41,61 \\
\hline & Control & 80 & 75,31 & 80,06 & 72,29 & 73,13 & 70,75 & 81,6 & 71,94 & 80,34 \\
\hline \multirow{2}{*}{$\begin{array}{l}\text { Franks } \\
2003\end{array}$} & $\begin{array}{l}\text { Chronic } \\
\text { wounds }\end{array}$ & $\begin{array}{l}11 \\
8\end{array}$ & 41,5 & 29,6 & 53,3 & 54,9 & 46,3 & 56,5 & 69,1 & 57,1 \\
\hline & Control & 11 & 63,0 & 50,7 & 65,5 & 58,2 & 48,7 & 78,6 & 73,2 & 84,9 \\
\hline $\begin{array}{l}\text { Jull } \\
2004\end{array}$ & $\begin{array}{l}\text { Chronic } \\
\text { wounds }\end{array}$ & 23 & 43,2 & 49,5 & 55,3 & 59,2 & 53,2 & 69,9 & 76,2 & 68,9 \\
\hline
\end{tabular}

Table 3. Characteristics of the included cost studies presented by wound type ( $\mathrm{n}=11)$

\begin{tabular}{|l|l|l|l|l|l|l|}
\hline Referenc & Cou & Typ & Eco & An & Cost components & \\
\hline
\end{tabular}




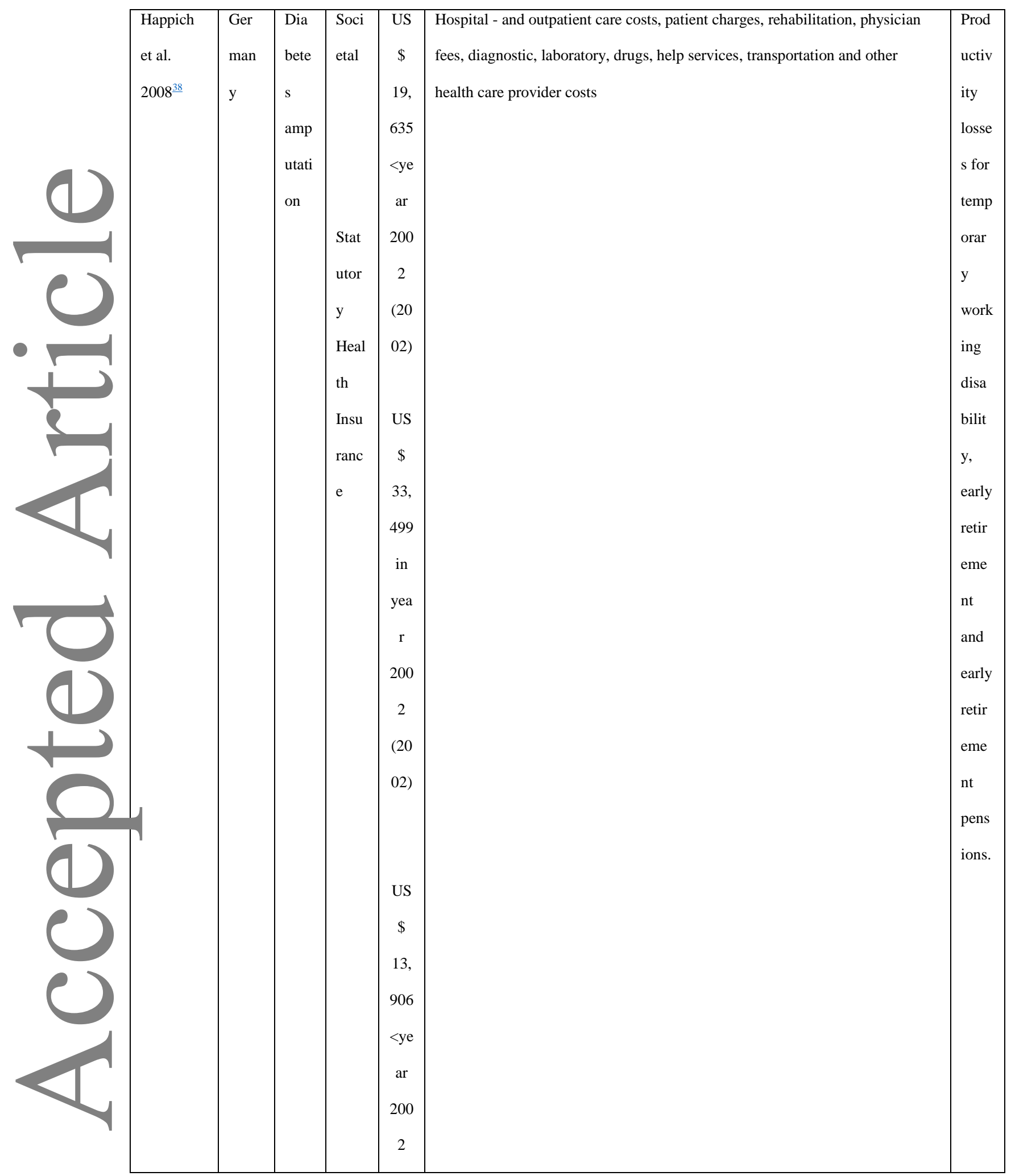




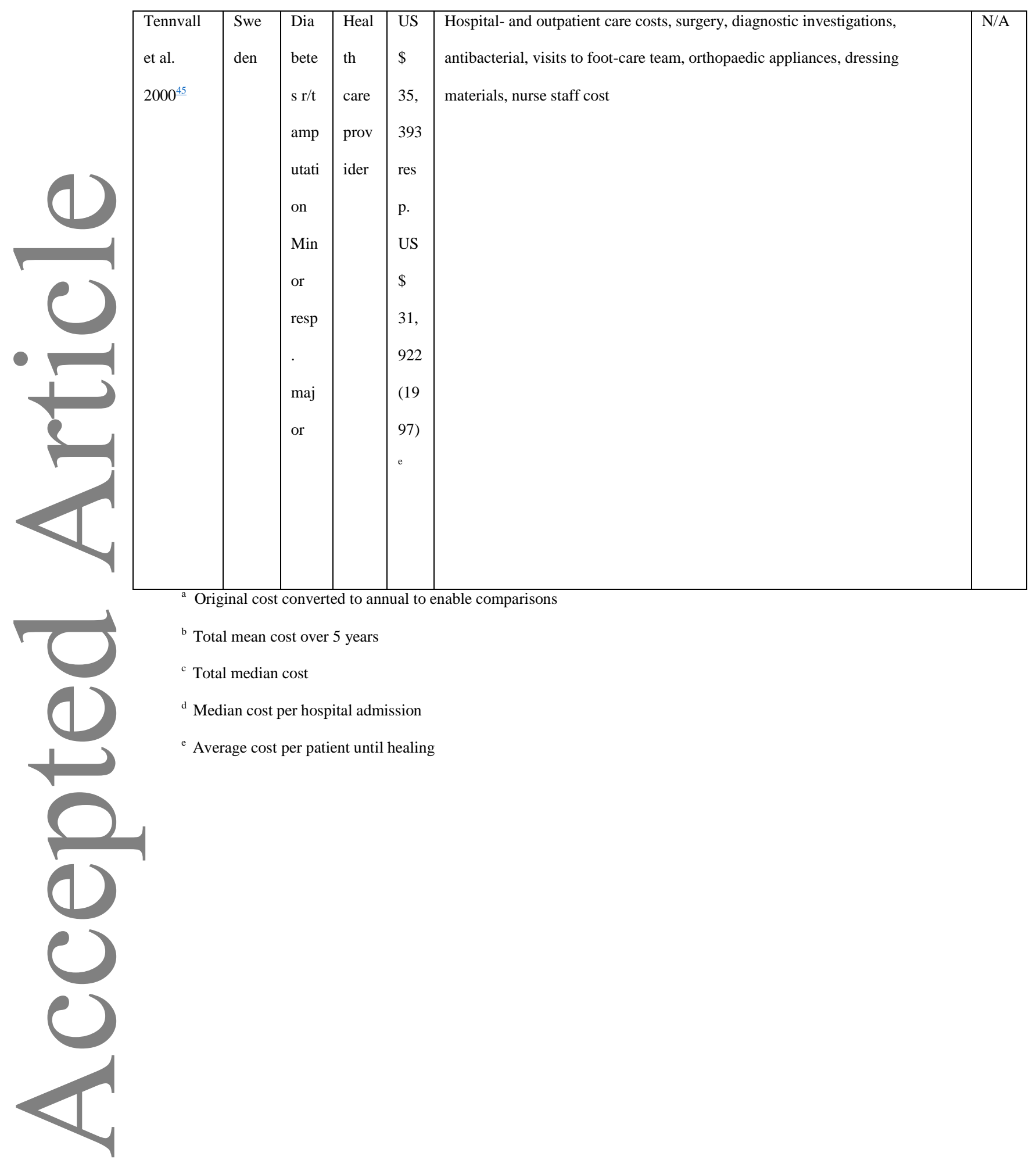

